\title{
Stress Avoidance in Hiatus
}

\author{
Anya Lunden \\ College of William \& Mary
}

\section{Introduction}

Segment-based syllable weight has been proposed to be calculated by either rhyme segments (McCarthy, 1979) or by intervals (Steriade, 2012). An interval is defined as the vocalic material of a syllable and all following segmental material until the vowel of the following syllable. The two theories parse segments into the same domains in two cases: word-finally, ${ }^{1}$ and for the first vowel of two adjacent vowels in different syllables, i.e., in hiatus. While the weight domain is the same for the two theories in cases of hiatus (consisting of just a short vowel, ' $\mathrm{V}$ '), the categorization of weight is different. While a short vowel alone is considered "light" in rhyme-based weight, it is considered "extra-light" in interval-based weight, as "light" intervals consist of a vowel and a following onset consonant. A comparison of (some) interval- and rhyme-based weights and domains is given in (1). Periods denote syllable boundaries. All intervals are delineated with bullets, and the interval of interest and the corresponding weight domain in Rhyme Theory are underlined.

(1) Weight domains comparison

\begin{tabular}{lll} 
& Intervals & Rhymes \\
\hline heavy & $\mathrm{C} \bullet \underline{\mathrm{VC}} \cdot \mathrm{C} \bullet \mathrm{V} \bullet$ & $\mathrm{CVC} . \mathrm{CV}$ \\
light & $\mathrm{C} \bullet \underline{\mathrm{V} . \mathrm{C} \bullet \mathrm{V} \bullet}$ & $\mathrm{C} \underline{\mathrm{V}} . \mathrm{CV}$ \\
extra light & $\mathrm{C} \bullet \underline{\mathrm{V} .} \bullet \mathrm{V} \bullet$ &
\end{tabular}

Steriade (2012) shows data from two languages which avoid stressing the first syllable in hiatus, when that syllable position would normally be expected to bear the stress. Karonven (2005) found penultimate secondary stress normally in five-syllable monomorphemic words in Finnish ${ }^{2}$ but antepenultimate in the case of final hiatus. Lunden (2006) found penultimate stress normally on vowel-final words in Norwegian but antepenultimate in the case of final hiatus. Examples from both languages are given in (2). (Also see (Steriade, 2017:18) for additional languages which avoid stressing the first of two vowels in hiatus.)

\begin{tabular}{|c|c|c|c|c|}
\hline & ... V.CV́.CV\# & ...CV́.CV.V\# & & \\
\hline $\begin{array}{l}\text { Finnish } \\
\text { Norwegian }\end{array}$ & $\begin{array}{ll}\text { kó.les.te.rò.li } & \text { 'cholesterol' } \\
\text { ba.gái.fe } & \text { 'luggage' }\end{array}$ & $\begin{array}{l}\text { té.le.vì.si.o } \\
\text { fó:.li.e }\end{array}$ & $\begin{array}{l}\text { 'televison' } \\
\text { 'foil' }\end{array}$ & $\begin{array}{l}\text { Karonven } 2005 \\
\text { Lunden } 2006\end{array}$ \\
\hline
\end{tabular}

Steriade (2012) posits that stress avoidance in cases of hiatus as in (2) is predicted by Interval Theory, as it involves stress avoiding a very light weight domain ('V'), in favor of a bigger one ('V.C'). Steriade (2017) further addresses the avoidance, discussing examples explained by assuming a lesser weight for a pre-vocalic vowel compared to a pre-consonantal vowel.

This paper explores a different, albeit potentially compatible, motivation for the stress pattern seen with instances of hiatus, such as those in (2). Namely, that there is a perceptual basis for the observed stress

\footnotetext{
* I would like to thank Nick Kalivoda for helpful discussion at multiple stages of this work and Marion Learner for assistance in carrying out the study. I also thank the attendees of AMP 2017 for helpful comments and questions.

1 See Lunden (2017) for a comparison of rhyme and interval durations with respect to the weight of syllables in final position.

2 Many sources describe Finnish as having secondary stress on every other syllable after the initial, primary-stressed syllable. Karonven argues that these cases involve morphologically complex words, and that the pattern for longer monomorphemic words places secondary stress on the penult.
} 
avoidance: The longer duration typically present in a stressed vowel is more difficult to perceive directly before another vowel.

A perception study was run using nonce words read by a native Norwegian speaker, with and without hiatus, where each word was pronounced twice, once with antepenultimate stress and once with penultimate stress. Norwegian has the requirement that stressed syllables must be heavy, and so a short stressed vowel will undergo vowel lengthening. The experiment was run on native English speakers to test the relative confusability of the word types. (Although English is not considered to have phonological vowel lengthening, duration is a strong cue to stress in the language (Sluijter \& van Heuven, 1996).)

The hypothesis put forward here is that the configuration [ $\left.\hat{V}^{\prime} . \mathrm{V}\right]$ is a type of context-sensitive markedness: the length of the first vowel is more difficult to perceive when the vowel abuts another vowel. The perception study is next presented and discussed, followed by a comparison of the duration of the rhymes and intervals of the stimuli used in the perception study. The results are then examined for compatibility with Interval Theory.

\section{Methods}

2.1 Participants Results are reported from 28 native English speakers (average age=19). All were undergraduates at the College of William \& Mary and all received participant pool credit. (An additional 12 participated but were excluded as discussed in $\S 2.3$.)

2.2 Stimuli Forty three-syllable nonce words were read in Norwegian sentences by a native Norwegian speaker (age 42, from the Vest-Agder region of Norway), with antepenultimate stress and again with penultimate stress, creating a total of 80 stimuli. Twenty of the words had final hiatus (i.e. were of the shape CV.CV.V) and twenty did not (i.e. were of the shape CV.CV.CV). The final two vowels were matched across hiatus and non-hiatus words and were one of four sequences. Example stimuli for each category are shown in (3). (See Appendix A for a complete list.) Note that $[\mathrm{u}]$ in Norwegian is distinct from $[\mathrm{u}]$ and is extra round.

(3) Sample stimuli for each of the four final vowel combinations

\begin{tabular}{lll} 
vowels & in hiatus & not in hiatus \\
\hline i-a & køsia & sikima \\
i-u & bymiu & læmisu \\
i-e & dapie & sæbise \\
e-a & sapea & pekela
\end{tabular}

The words were extracted from generic-content sentences, as in (4).
a. En nolipe ble fanget
a nonce_word was found
b. En demia var snakket om
a nonce_word was talked about

The native Norwegian speaker read series of sentences like those in (4) in blocks by stress location, with explicit instructions about the stress location and sample real Norwegian words with that stress pattern preceding each block. While three-syllable words with hiatus typically have antepenultimate stress in the language, there are exceptions, particularly with names, such as Ma.rí.a and To.bá.is, and so all pronunciations reflected occurring patterns in the language. The full set of sentences were read twice, with only the second pronunciation being used in the study. Throughout the recordings sentences were re-read if needed in order to be produced smoothly, i.e. with the nonce word sounding like a natural word integrated into the carrier sentence fluently. Norwegian has a lexical pitch accent, but all words were read with the neutral accent (where pitch aligns with the stressed syllable, as opposed to the marked accent, where high pitch is delayed to the syllable following the primary stress syllable).

2.3 Procedure Subjects were given the 80 words as a Multiple Forced Choice task in Praat (Boersma \& Weenink, 2015), with instructions that they would hear three-syllable words in a foreign language and they 
should identify the stress as being on the first or second syllable for each word. Before taking the study, participants heard two sample words (one with hiatus, one without) with antepenultimate syllable stress (as examples of "first syllable stress") and the same two sample words with penultimate stress (as examples of "second syllable stress").

For their data to be useable, subjects needed to have correctly identified stress reasonably reliably. Twelve subjects were excluded for failing to correctly identify the stress in at least 50 of the 80 words presented (binomial probability of at least 50/80: $p=0.016$ ).

\section{Results}

The proportion of correct responses is given in (5). It can be seen that listeners showed an overall preference for identifying antepenultimate stress; but we see, as the perceptional confusability hypothesis would predict, the fewest correct identifications of penultimate stress in the presence of hiatus.

Percent of correctly-identified stress, by position and hiatus-status of the nonce word

\begin{tabular}{l|ll} 
& Antepenult & Penult \\
\hline No hiatus & $89.82 \%$ & $76.96 \%$ \\
Final hiatus & $86.43 \%$ & $66.43 \%$
\end{tabular}

A binary logistic regression was run with response as the dependent variable (DV), fixed factors stress and hiatus, and with subject as a blocking factor. The interaction term stress $*$ hiatus was significant $(p<$ 0.001), consistent with the observation that hiatus results in fewer correct identifications of penultimate stress. (Model is given in (i) in Appendix B.) While there was a slightly higher percentage of correct antepenultimate stress identifications when the word did not contain hiatus, post-hoc pairwise comparison of stress*hiatus using Fisher's least significant difference (LSD) adjustment finds that there is not a significant difference between these cases and identifications of antepenultimate stress when the word did contain hiatus $(p=$ 0.078). The pairwise comparisons show that there is, however, a significant difference between identifications of penultimate stress, depending on the presence or absence of hiatus $(p<0.001)$, as shown visually in $(6)$.

(6) Percent of correctly-identified stress placements

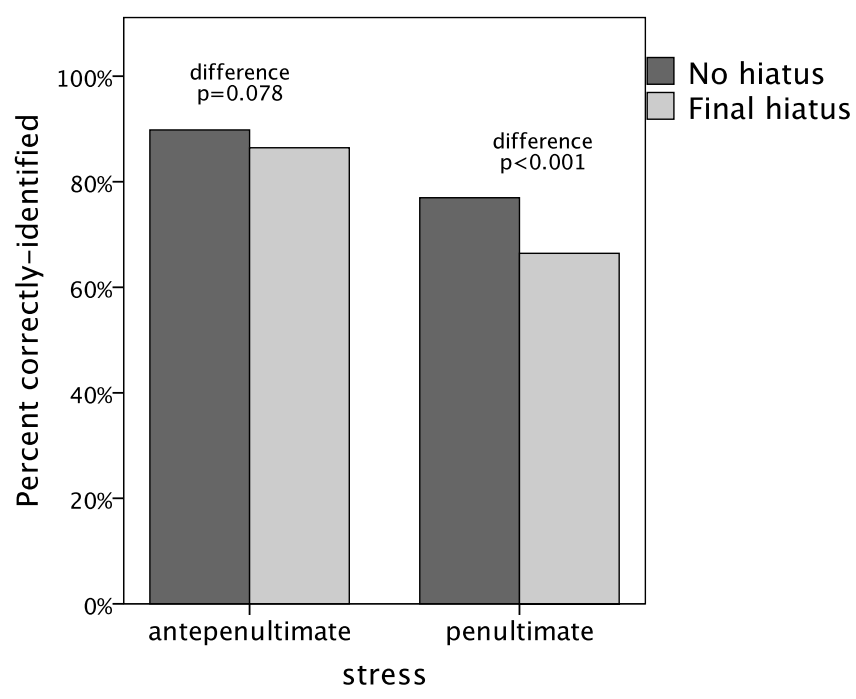

Thus we see that despite the allophonic vowel lengthening of the stressed syllable in all the nonce words, stress on the penult is significantly less likely to be correctly identified when it occurs pre-vocalically. A binary logistic regression like the one reported above, but with the additional factor vowel sequence failed to find any significant interaction between hiatus and vowel_sequence $(p=0.441)$, although in fact, penultimate stress with the vowel sequence [i-u] was equally well perceived in a hiatus configuration as in the absence of hiatus. The breakdown of correctly-identified cases of penultimate stress by vowel sequence is shown in (7). Despite the lack of a significant interaction term, pairwise comparisons of hiatus $*$ stress $*$ vowel_sequence 
were examined to determine the significance values shown for bar pairs in the graph (between penultimate stress cases, differing by hiatus-status, for each vowel pair). (Model is given (ii) in Appendix B.)

(7) Percent of correctly-identified penultimate stress placements, by final vowel combinations

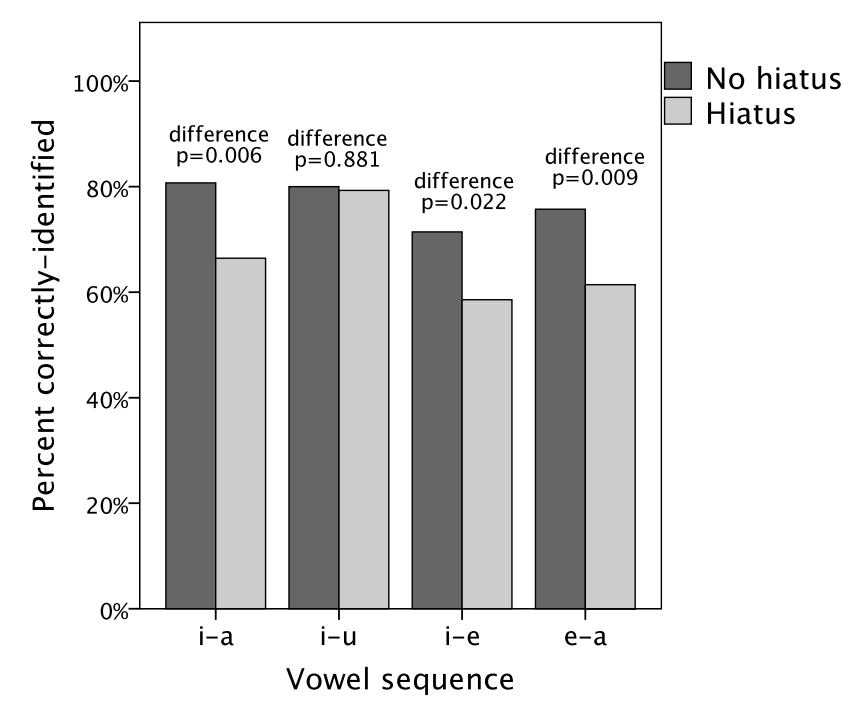

While the difference in identification of the correct stress is significantly different in three of the four vowel sequences, it is not not different for one, [i-u]. It is not clear why this sequence is exempt from the effect. Steriade (2017) notes that [i] seems to be particularly prone to stress avoidance when it is the first vowel in a hiatus sequence, but this would, if anything, predict that the [e-a] sequence would be the one to behave differently. Listening to, and looking spectrographically at the stimuli it is not clear what might make the [i-u] cases different. They do not seem to have a transitional glide, for example. Ideally, further perceptional studies would be carried out, both with more vowel sequences and also with different language populations.

\section{Rhyme/Interval comparison of the stimuli}

The fact that stress is more difficult to perceive on the penult when there is a following adjacent vowel supports the hypothesized perceptual motivation for avoiding stress in hiatus. Even though stressed syllables have undergone vowel lengthening in Norwegian, Interval Theory predicts that the weight domain [V:] is lighter than [V:.C], as "a lengthened vowel in hiatus still falls short of the optimal bimoraic weight" (Steriade, 2017:8). Weight, in both Rhyme and Interval Theory, is linked to duration, as the more segmental/moraic content present, the greater the weight. ${ }^{3}$ In order to establish the actual relative durations, the 80 stimuli were measured for both rhymes and intervals using TextGrids in Praat, and durations extracted using a Praat script (Hirst, 2009).

The rhyme durations pattern as you would expect for words in which the only heavy syllable is the one bearing stress. When stress is antepenultimate, the longest rhyme is the antepenult; when the stress is penultimate, the longest rhyme is the penult, whether or not the final two syllables involve hiatus, as shown in (8).

\footnotetext{
3 The link between segmental/moraic content is coarser in Rhyme Theory, whereas Interval Theory makes more finegrained distinctions; see Steraide (2012, 2017).
} 
(a) No hiatus: CV.CV.CV

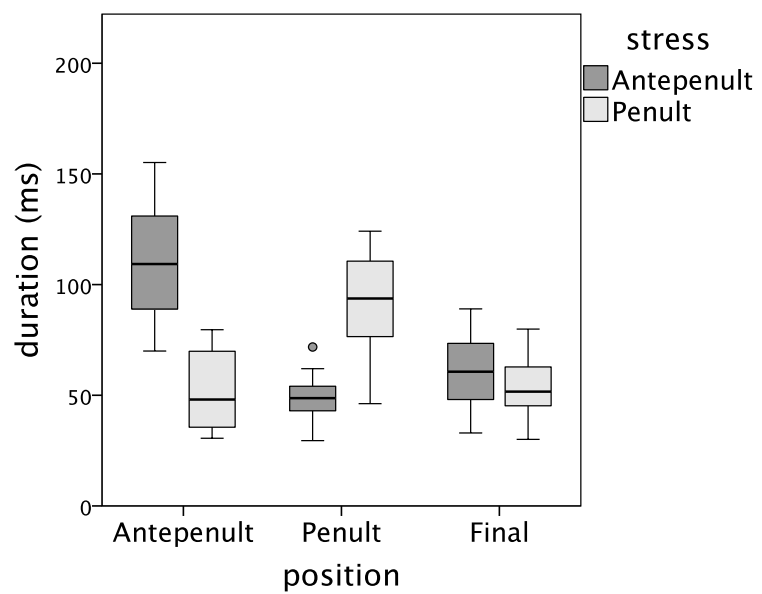

(b) Hiatus: CV.CV.V

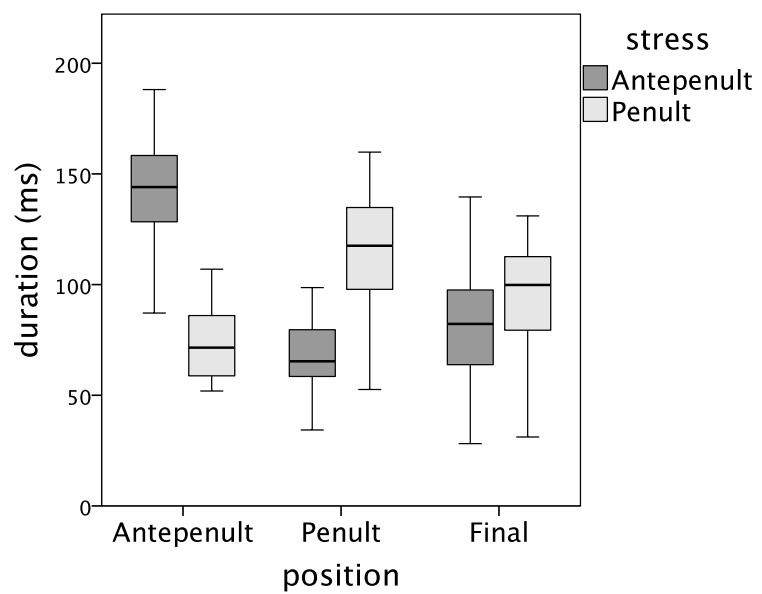

When we turn to examining the durations of intervals, however, we see a strikingly different picture, as shown in (9). The antepenultimate interval is always notably long, even when stress is penultimate: only slightly shorter than the penultimate interval in the absence of hiatus, and much longer than the penultimate interval in the presence of hiatus. (Note that range for interval durations is larger than that of rhyme durations because there is more potential length, given the inclusion of onset consonants (in the duration of the preceding interval).)

(9) Interval durations of stimuli (0-350 ms.)

(a) No hiatus: CV.CV.CV

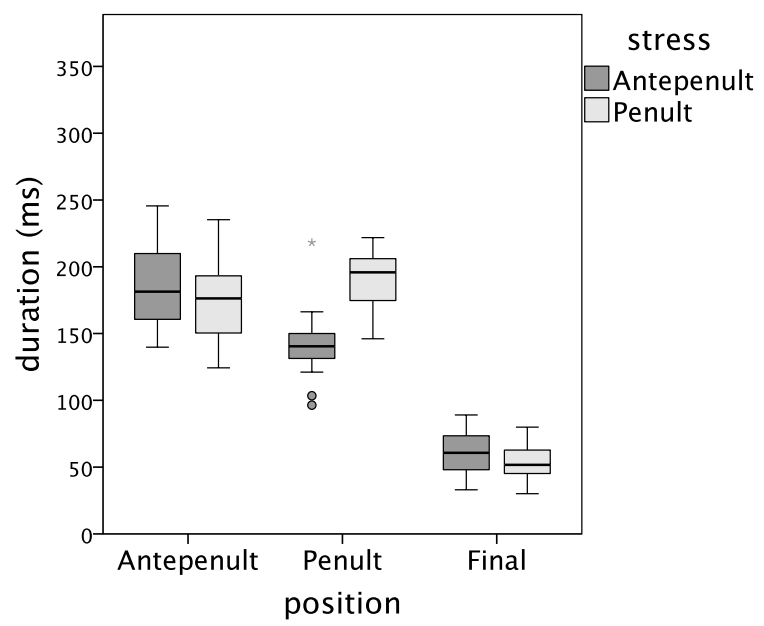

(b) Hiatus: CV.CV.V

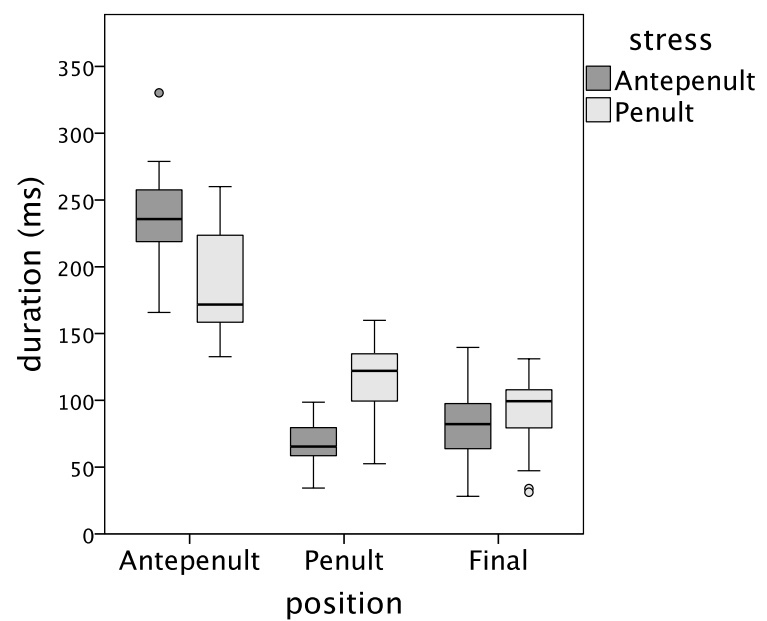

While the comparison of the (b) graphs between (8) and (9) might seem to suggest that intervals are not capturing the stressed domain correctly in cases of penultimate stress under hiatus, it could be argued that it is in fact this lack of durational prominence of the penultimate interval, even with the additional lengthening due to stress, that makes stress in this position unsuitable for stress. However, looking at the relative interval durations in the absence of hiatus ((a) in (9)), the lack of clear prominence of the penultimate interval under stress and the consistent prominence of the antepenultimate interval, regardless of stress, is problematic. A Generalized Linear Model was run with intervalduration as DV and factors stress, position, hiatus. (Full model is given in Appendix C.) The post-hoc pairwise comparison using Fisher's LSD adjustment of stress $*$ position $*$ hiatus finds no significant difference $(p=0.151)$ between antepenultimate interval durations 
in the absence of hiatus and a marginally significant difference $(p=0.047)$ between antepenultimate and penultimate intervals under penultimate stress in the absence of hiatus.

Under Interval Theory, any increase in duration in the onset of a stressed syllable (except of the initial syllable) is assigned to the preceding interval. The stimuli regularly show additional length in the onset of the penultimate syllable when the penultimate syllable is stressed. Boxplots of the durations of the penultimate consonants for all 80 penultimate onsets in the stimuli by stress position are shown in (10). ${ }^{4}$

Duration of penultimate onset consonants, by stress position.

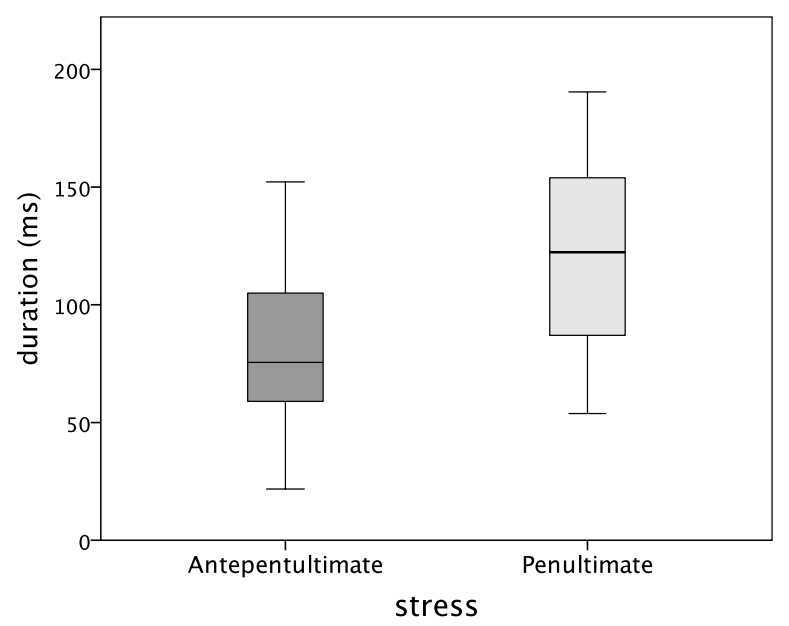

While the study was not set up to examine consonant type, an effort was made to vary consonant types and positions. (See (ii) in Appendix D for numbers of each consonant type in the stimuli.) The durations of the penultimate onset consonants under antepenultimate and penultimate stress are broken out by consonant type in (11).

(11) Duration of penultimate onset consonants, by consonant type and stress position

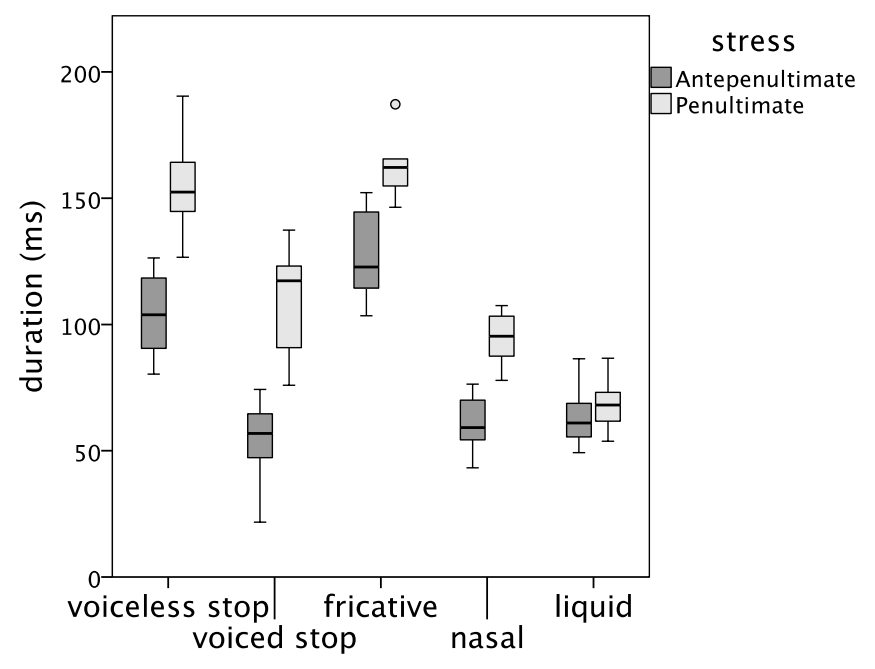

We see a particularly large increase in duration under penultimate stress for voiceless stops in the onset of the penultimate syllable. This is because in Norwegian, as in English, voiceless stops become aspirated when they occur at the beginning of a stressed syllable. The increase in consonantal duration, however, is

\footnotetext{
4 A Generalized Linear Model run with penultimate_consonant_duration as the DV and factors stress and hiatus, found a significant effect of stress $(p<0.001)$ but not of hiatus $(p=0.262)$ or of the interaction term $(p=0.206)$. (See (i) in Appendix D.) Therefore all penultimate consonants, regardless of whether they came from word with hiatus or not, are included in this examination.
} 
notably pervasive across the different consonant types, occurring additionally with voiced stops, (voiceless) fricatives, and nasals. ${ }^{5}$

The increase in duration of the onset consonant under stress explains the consistently long durations found for the antepenultimate intervals in (9). However, it would seem to be a problem for Interval Theory, as the increase in duration due to stress is assigned to an unstressed interval.

\section{Conclusion}

The perception study found support for the perceptual hypothesis put forward for stress avoidance in hiatus. As predicted, stress on Norwegian-pronounced words was more difficult for listeners to correctly identify when stress was on the first of two vowels in hiatus. The lack of a clear distinction between the final two vowels presumably leads to confusion as to the relative prominence of the penult, compared to cases where there is an intervening consonant. This is illustrated in (12) and (13) with sample nonce words from the study.

Sample nonce word with hiatus: [çønie]

(a) Antepenultimate stress

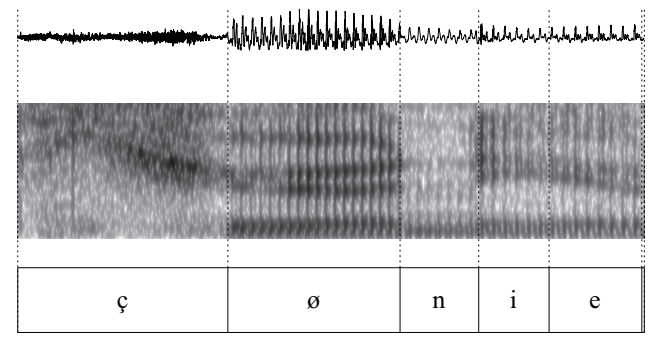

(13)

Sample nonce word without hiatus: [lunige] (b) Penultimate stress

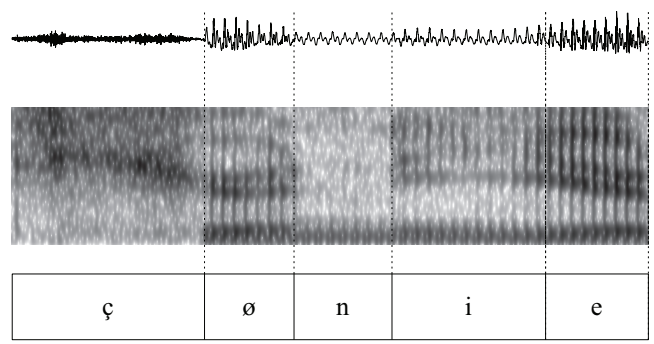

(a) Antepenultimate stress



(b) Penultimate stress

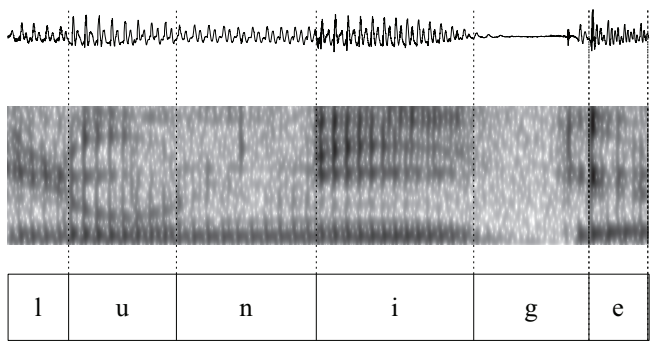

The stress-status of the penultimate syllable is expected to be the most confusable in the case of (12-b), as stress occurs on a vowel directly preceding another vowel, and so will presumably have the least clear duration-based cues to stress. In (12-a), where we see final hiatus but stress on the antepenultimate syllable, the length of the stressed vowel is clearly delineated by the following consonant. In (13-b), where we see penultimate stress not in a hiatus configuration, the duration that belongs to the penultimate vowel is again clear because of the following consonant. (A case of antepenultimate stress without final hiatus is given in (13-a) to complete the picture of the four word types used in the perception study.)

The results of the perception experiment suggest that avoidance of stress in the first syllable of a hiatus configuration is a perceptual issue. While this motivation is potentially compatible with Interval

5 Pairwise comparisons of stress $*$ consonant type found penultimate onsets were significantly longer when the penultimate syllable was stressed $(p<0.001)$ for all consonant types except liquids, which were not found to be significantly different $(p=0.533$ ). (Post-hoc analysis from a Generalized Linear Model run with penultimate_consonant_duration as DV and factors stress and consonant type; see (iii) in Appendix D.) 
Theory's categorization of such weight domains, the consistent relative strength of the antepenultimate interval regardless of stress is problematic for Interval Theory, which lacks a clear mapping from durational strength to word prominence.

\section{Appendix A: Stimuli}

The Norwegian spelling, where different, is given in angle brackets.

\begin{tabular}{|c|c|c|c|c|}
\hline Vowel pattern: & {$[\mathrm{i}-\mathrm{a}]$} & {$[\mathrm{i}-\mathrm{u}]$} & [i-e] & {$[\mathrm{e}-\mathrm{a}]$} \\
\hline no hiatus & $\begin{array}{l}\text { bidia } \\
\text { bumia }<\text { bomia }> \\
\text { demia } \\
\text { køsia } \\
\text { skepia }\end{array}$ & $\begin{array}{l}\text { bymiu }<\text { bymio }> \\
\text { fipiu }<\text { fipio }> \\
\text { natiu }<\text { natiu }> \\
\text { suriu }<\text { suriu }> \\
\text { vesiu }<\text { vesiu }>\end{array}$ & $\begin{array}{l}\text { dapie } \\
\text { kjønie } \\
\text { Jælie }<\text { sjælie }> \\
\text { musie }<\text { mosie }> \\
\text { kurie }<\text { kurie }>\end{array}$ & $\begin{array}{l}\text { dilea } \\
\text { jutea }<\text { jutea }> \\
\text { mæsea } \\
\text { sapea } \\
\text { fælea }<\text { sjælea }>\end{array}$ \\
\hline hiatus & $\begin{array}{l}\text { dupifa } \\
\text { çenipa }<\text { kjenipa }> \\
\text { musiba }<\text { mosiba }> \\
\text { sikima } \\
\text { tabika }\end{array}$ & 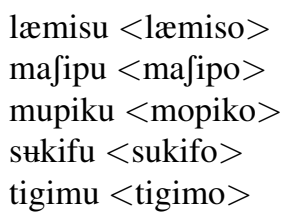 & $\begin{array}{l}\text { lunige }<\text { lonige }> \\
\text { nølipe } \\
\text { pytine } \\
\text { sæbise } \\
\text { tamiçe }<\text { tamikje }>\end{array}$ & $\begin{array}{l}\text { kubema }<\text { kobema }> \\
\text { milesa } \\
\text { nodeka }<\text { nådeka }> \\
\text { pekela } \\
\text { tanepa }\end{array}$ \\
\hline
\end{tabular}

\section{Appendix B: Binary logistic regression, perception experiment data}

Models were run with response as DV, and data was blocked by subject.

(i)

\begin{tabular}{llll} 
& Wald $\chi^{2}$ & df & \multicolumn{1}{l}{$p$} \\
\hline (intercept) & 87.682 & 1 & $<0.001$ \\
stress & 660.645 & 1 & $<0.001$ \\
hiatus & 0.777 & 1 & 0.378 \\
stress $*$ hiatus & 13.883 & 1 & $<0.001$
\end{tabular}

(ii)

\begin{tabular}{lllr} 
& Wald $\chi^{2}$ & df & \multicolumn{1}{c}{$p$} \\
\hline (intercept) & 85.081 & 1 & $<0.001$ \\
stress & 651.042 & 1 & $<0.001$ \\
hiatus & 0.594 & 1 & 0.441 \\
vowel_sequence & 6.312 & 3 & 0.097 \\
stress*hiatus & 12.998 & 1 & $<0.001$ \\
stress*vowel_sequence & 11.339 & 3 & 0.010 \\
hiatus $*$ vowel_sequence & 2.693 & 3 & 0.441 \\
stress $*$ hiatus $*$ vowel_sequence & 4.662 & 3 & 0.198
\end{tabular}

\section{Appendix C: Generalized Linear Model; DV: interval durations of the stimuli}

\begin{tabular}{lllr} 
& Wald $\chi^{2}$ & df & \multicolumn{1}{c}{$p$} \\
\hline (intercept) & 5914.927 & 1 & $<0.001$ \\
stress & 4.415 & 1 & 0.036 \\
hiatus & 0.977 & 1 & 0.323 \\
position & 873.005 & 2 & $<0.001$ \\
stress $*$ hiatus & 0.603 & 1 & 0.437 \\
stress*position & 86.681 & 2 & $<0.001$ \\
hiatus*position & 208.387 & 2 & $<0.001$ \\
stress $*$ hiatus*position & 8.631 & 2 & 0.013
\end{tabular}




\section{Appendix D: Onset consonants of the penultimate syllable in the stimuli}

(i) Generalized Linear Model with durations of the penult consonant as DV to examine if hiatus-status has an effect

\begin{tabular}{lllr} 
& Wald $\chi^{2}$ & df & \multicolumn{1}{c}{$p$} \\
\hline (intercept) & 719.435 & 1 & $<0.001$ \\
hiatus & 1.256 & 1 & 0.262 \\
stress & 23.955 & 1 & $<0.001$ \\
hiatus $*$ stress & 1.599 & 1 & 0.206
\end{tabular}

(ii) Numbers of each consonant type in 40 stimuli words. (Each occurs twice in the stimuli: Once in the antepenultimate stress version of the word and once in the penultimate stress version.)

\begin{tabular}{ll} 
Consonant type & number \\
\hline voiceless stop & 12 \\
voiced stop & 6 \\
fricative & 6 \\
nasal & 6 \\
liquid & 7
\end{tabular}

(iii) Generalized Linear Model with durations of the penult consonant as DV

\begin{tabular}{llll} 
& Wald $\chi^{2}$ & df & $p$ \\
\hline (intercept) & 3711.895 & 1 & $<0.001$ \\
stress & 120.944 & 1 & $<0.001$ \\
consonant_type & 366.377 & 4 & $<0.001$ \\
stress*consonant_type & 29.913 & 4 & $<0.001$
\end{tabular}

\section{References}

Boersma, Paul \& David Weenink (2015). Praat: doing phonetics by computer. Computer program. URL http://http://www. fon.hum. uva.nl/praat/. Version 5.4.22, retrieved 8 October 2015.

Hirst, Daniel (2009). Praat script analyse tier, version 8 July 2009. Retrieved 23 June 2011.

Karvonen, Dan (2005). Word Prosody in Finnish. Ph.D. thesis, University of California, Santa Cruz, Santa Cruz, CA.

Lunden, Anya (2017). Syllable weight and duration: A rime/interval comparison. Proceedings of the Linguistic Society of America, vol. 2, 1-12.

Lunden, S.L. Anya (2006). Weight, Final Lengthening and Stress: A Phonetic and Phonological Case Study of Norwegian. Ph.D. thesis, University of California, Santa Cruz.

McCarthy, John (1979). Formal Problems in Semitic Phonology and Morphology. Ph.D. thesis, Massachusetts Institute of Technology, Cambridge, MA.

Sluijter, Agaath \& Vincent van Heuven (1996). Acoustic correlate of linguistic stress and accent in Dutch and American English. Proceedings of the fourth international conference on spoken language processing (ICSLP), 630-633.

Steriade, Donca (2012). Intervals vs. syllables as units of linguistic rhythm. Handouts, EALING, Paris.

Steriade, Donca (2017). CiV length, derived environments and the weight of CV. M.s., MIT. 